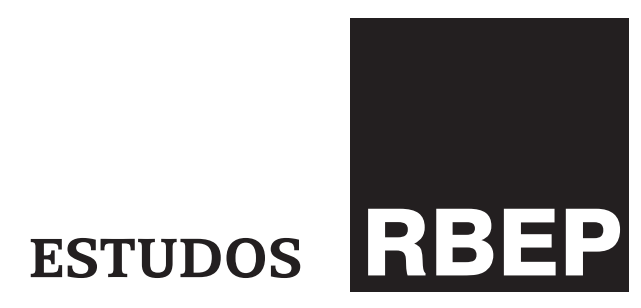

\title{
Relação entre educação básica e educação superior: algumas considerações com base em estudo exploratório do Ideb em Mato Grosso do Sul*
}

Giselle Cristina Martins Real

http://dx.doi.org/10.1590/S2176-6681/321812028

\section{Resumo}

Com caráter exploratório, visa explicitar as relações entre a Universidade Estadual de Mato Grosso do Sul e as redes municipais com bons resultados no Índice de Desenvolvimento da Educação Básica (Ideb) localizadas no interior do Estado. Trata-se de uma pesquisa qualiquantitativa. Como resultados, constatou-se que a realização de programas de formação inicial em serviço produz efeitos na titulação dos professores, além de repercussões indiretas, que contribuem para a formação continuada. Pode-se concluir que, caso haja políticas institucionais focalizadas, amplia-se o potencial de efetividade das ações universitárias nesses espaços.

Palavras-chave: política educacional; avaliação educacional; formação de professores. 


\section{Abstract \\ The relationship between basic education and higher education: some considerations based on an exploratory study of Basic Education Development Index (Ideb) in Mato Grosso do Sul}

This exploratory study aims to bring up the relationships between the Universidade Estadual de Mato Grosso do Sul and the countryside municipal public schools with good results in the Basic Education Development Index (Ideb). The study is a qualitative-quantitative research. It was found that the implementation of initial training programs in-service takes effect upon teachers' title, as well as indirect effects that contribute to their continuing education. It can be concluded that, in case there are focused institutional policies, the potential of effectiveness of university actions in these places is expanded.

Keywords: educational policies; educational evaluation; teacher education.

\section{Introdução}

O contexto brasileiro, desde os anos 2000, apresenta um conjunto de ações e medidas governamentais que permitem inferir a intensificação da busca de qualificação da educação, especialmente da educação básica. Esse processo tem, como um de seus pontos congruentes, a adoção da avaliação como estratégia pública privilegiada.

Partindo do pressuposto de que a avaliação contribui para o processo de qualificação educacional, e tomando os resultados de avaliações em larga escala analisados pela literatura científica (Alves, 2009; Brooke; Soares, 2008; Parandekar; Oliveira; Amorim, 2008), observa-se que existem indicadores que apontam para nexos entre educação superior e educação básica nos bons resultados do desenvolvimento educacional, configurados, sobretudo, na formação de professores, conforme explicita Alves (2008, p. 429):

A variável indicadora do eixo formação docente (professores com ensino superior) apresenta um impacto positivo e significativo no desempenho médio das redes de ensino. $\mathrm{O}$ aumento de 10 pontos percentuais na proporção de turmas com professores que cursaram o ensino superior acarreta um acréscimo médio de 0,57 pontos no desempenho médio das redes de ensino. [...]. No âmbito da literatura nacional, Albernaz, Ferreira e Franco (2002) reportaram efeito positivo do nível de formação docente sobre a eficácia escolar, em estudo baseado em dados do Saeb 1999. Resultados convergentes foram encontrados por Soares (2004), com dados do Saeb 2001 para a $8^{a}$ série do ensino fundamental e por Machado (2005), com dados do Saeb 2003 para a $4^{\mathrm{a}}$ série do ensino fundamental.

Esses dados explicam a realização do presente estudo, de caráter exploratório, que procurou compreender a relação entre os municípios 
sul-mato-grossenses localizados no interior, considerados como detentores de bons resultados no Índice de Desenvolvimento da Educação Básica (Ideb), e a presença, nesses espaços, da Universidade Estadual de Mato Grosso do Sul (UEMS), cuja criação é justificada pela busca por melhoria da qualidade na educação básica no interior do Estado.

A UEMS foi implantada em 1994 com formato multi-campi, presente em 15 municípios do Estado de Mato Grosso do Sul, sendo administrada com recursos do governo do Estado. Atende uma população significativa, que representa 58,97\%, num Estado que conta com 79 municípios. Os municípios com unidade universitária ${ }^{1}$ instalada são: Dourados (sede da universidade), Campo Grande (capital do Estado), ${ }^{2}$ Naviraí, Paranaíba, Amambai, Mundo Novo, Glória de Dourados, Ivinhema, Nova Andradina, Ponta Porã, Coxim, Jardim, Maracaju, Cassilândia e Aquidauana.

Sua missão, no momento de sua implantação, consistia em "gerar e disseminar o conhecimento, voltada para a interiorização e com compromisso em relação aos outros níveis de ensino" (Mello, 2010, p. 6). Portanto, sua implantação explicita seu compromisso com o desenvolvimento da educação básica no interior do Estado.

Os critérios que selecionaram as redes municipais com bons resultados no Ideb em Mato Grosso do Sul consideraram dois grupos, sendo um que incluiu cinco municípios com maior Ideb em 2007 e outro que incluiu cinco municípios com maior variação do Ideb nos anos de 2005 e 2007. A pesquisa focalizou as séries iniciais do ensino fundamental e municípios com mil ou mais matrículas em 2005. Os municípios selecionados por esses critérios em Mato Grosso do Sul foram: Campo Grande, São Gabriel do Oeste, Chapadão do Sul, Naviraí, Paranaíba - com maiores resultados em 2007 -, Bonito, Paranhos, Amambai, Bela Vista e Aparecida do Taboado com maior variação entre 2005 e 2007 (Sousa; Oliveira; Alavarse, 2011).

Dos municípios em que a UEMS está instalada, quatro constam entre os considerados na amostra como detentores de bons resultados no Ideb, que são: Amambai, Naviraí, Paranaíba e Campo Grande. A rede municipal de Campo Grande, capital do Estado, não é considerada no momento, já que o foco do trabalho está concentrado em municípios localizados no interior.

O diferencial do presente estudo está em explicitar as relações que se estabelecem entre redes municipais do interior do Estado e a universidade, considerando sua tripla função de ensino, pesquisa e extensão. Adotaram-se, como parâmetro procedimental, instrumentos da abordagem quali-quantitativa. Nesse sentido, além de dados estatísticos disponíveis em bases eletrônicas e outros produzidos baseando-se na coleta de dados locais, apoiou-se em resultados obtidos por meio de entrevistas ${ }^{3}$ aos gestores educacionais das redes municipais e da própria universidade, considerando o período de 2000 a 2007.

\section{A formação inicial de professores}

Em 2007, a UEMS ofereceu, em seu vestibular, 1.770 vagas em cursos de licenciatura para uma média anual de 13 mil jovens concluintes do ensino

\footnotetext{
${ }^{1}$ A UEMS adota o termo unidade universitária para a definição de seus campi fora de sede.

2 A unidade da UEMS na capital foi criada em período posterior ao da implantação da universidade no interior do Estado, o que implicou alterar a missão institucional a partir de 2012, conforme disposto no atual Plano de Desenvolvimento Institucional (PDI).

3 Todas as entrevistas foram concedidas a pesquisadores e transcritas por auxiliares bolsistas.
} 
médio, considerando os 15 municípios atendidos. Em 1998, em sua primeira turma de formandos, foram licenciados 221 alunos na UEMS e, em 2007, um total de 485, o que representa um quantitativo acima do dobro do total inicial, perfazendo um aumento de 119,45\% nas taxas de conclusão. Nesse período de dez anos, o número de concluintes nos cursos de licenciatura da UEMS chegou a 4.268 (Mello, 2010).

Pode-se observar, pelo perfil das vagas ofertadas pela instituição em 2007, que mais da metade, ou seja, 56,5\%, é de cursos de licenciatura, o que explicita o seu direcionamento para contribuir na formação de quadros para a educação básica, referenciado na missão institucional. No entanto, constatou-se, também, que algumas unidades universitárias não oferecem cursos de licenciatura, como é o caso de Ponta Porã e Aquidauana.

O processo de interiorização desenvolvido pela UEMS proporcionou formação de professores para as redes de educação básica nos dez municípios considerados com bons resultados no Ideb, mesmo naqueles em que não há unidade universitária instalada. Indícios desse processo podem ser observados nos dados estatísticos produzidos pelo Instituto Nacional de Estudos e Pesquisas Educacionais Anísio Teixeira (Inep), quando registram que, em 2007, havia 73,38\% dos professores com curso superior atuando nos anos iniciais do ensino fundamental (Brasil. Inep, 2008), enquanto em 1997, antes da primeira turma de formandos da UEMS, ${ }^{4}$ esse número era de 53,87\% (Brasil. Inep, 1999), o que representa um aumento de 19,58\% no nível de titulação dos docentes da educação básica em todo o Estado.

Os dados empíricos coletados in loco são mais explícitos na descrição da efetividade do processo de formação de professores para a educação básica no Estado.

Os efeitos das medidas institucionais podem ser observados pela presença de professores formados pela UEMS nas redes de educação básica, conforme apresentado na Tabela 1, que explicita a origem da formação dos professores que estão atuando junto às redes de educação dos municípios considerados.

Por esse dado, é possível observar que mesmo em municípios como Aparecida do Taboado, Paranhos e São Gabriel do Oeste, em que não há unidade da UEMS instalada, registram-se professores formados pela instituição; e nos municípios em que há a presença de unidade da UEMS - Amambai, Naviraí e Paranaíba -, há significativa incorporação de egressos dessa universidade junto à rede de educação básica, minorando os percentuais de egressos de instituições não universitárias privadas, o que explicita efeitos da universidade no desenvolvimento da educação básica no interior do Estado. No conjunto dos demais municípios, o que se observa é a formação majoritária dos professores pelas instituições privadas não universitárias, em que, a priori, há a dissociabilidade do ensino, da pesquisa e da extensão. 
Tabela 1 - Formação Inicial dos Professores que Estão Atuando na Educação Básica, nos Dez Municípios Selecionados no Estado de Mato Grosso do Sul em 2009

\begin{tabular}{|c|c|c|c|c|c|c|}
\hline \multirow{2}{*}{$\begin{array}{l}\text { Municípios com bons } \\
\text { resultados do Ideb }\end{array}$} & \multirow{2}{*}{$\begin{array}{c}\text { Sem } \\
\text { licenciatura }\end{array}$} & \multicolumn{4}{|c|}{ Graduados } & \multirow[b]{2}{*}{ Total } \\
\hline & & UEMS & $\begin{array}{c}\text { IES } \\
\text { públicas }\end{array}$ & $\begin{array}{c}\text { IES } \\
\text { privadas }\end{array}$ & $\begin{array}{l}\text { IES/outros } \\
\text { estados }\end{array}$ & \\
\hline Amambai & 36 & 104 & 8 & 97 & 37 & 282 \\
\hline Aparecida do Taboado & 0 & 5 & 6 & 10 & 78 & 99 \\
\hline Bela Vista & - & - & - & - & - & * \\
\hline Bonito & - & - & - & - & - & * \\
\hline Campo Grande & 8 & 22 & 195 & 1.612 & 69 & 1.906 \\
\hline Chapadão do Sul & - & - & - & - & - & $*$ \\
\hline Naviraí & 5 & 68 & 17 & 167 & 39 & 296 \\
\hline Paranaíba & 10 & 36 & 10 & 84 & 101 & 241 \\
\hline Paranhos & 32 & 2 & 4 & 54 & 19 & 111 \\
\hline São Gabriel do Oeste & 0 & 8 & 27 & 139 & 56 & 230 \\
\hline
\end{tabular}

Fonte: Mello, 2010

*O município não informou os números, embora tenha relatado a presença de professores formados
pela UEMS nas entrevistas.

A literatura da área educacional aponta que a formação se dá com melhor qualidade na universidade, em que há ensino, pesquisa e extensão articulados (Freitas, 2007; Cunha, 2004). Nesse sentido, "na universidade, ensino, pesquisa e extensão efetivamente se articulam, mas a partir da pesquisa, ou seja, só se aprende, só se ensina, pesquisando, construindo conhecimento" (Severino, 2009, p. 261).

Entre as ações institucionais desenvolvidas pela IES e voltadas para a formação inicial de professores, foi destacada nos depoimentos dos gestores a oferta do curso normal superior, que se constituiu em programa de formação de professores em serviço, por meio da realização de convênios específicos da universidade com as redes de educação básica.

Esse programa foi responsável pela graduação de 1.438 professores egressos da UEMS, o que implica 33,69\% do total de licenciados formados pela instituição no período de 1998 a 2007. Destaca-se que parte dos professores que estão atuando junto às redes de educação básica é oriunda desse curso.

O curso normal superior recebeu destaque nos depoimentos dos gestores da educação básica, conforme ilustra a declaração da secretária de Educação do município de Amambai ${ }^{5}$ - que atuou em duas gestões municipais, sendo uma no período de 2000 a 2003 e outra no período de 2008 a $2011-$, que, ao ser questionada sobre as parcerias e os convênios ${ }^{5}$ Entrevista realizada em 18
de agosto de 2009, quando se
autorizou o uso das informações. 
que contribuíram para o bom resultado do Ideb de sua rede, menciona a contribuição da UEMS:

[...] A UEMS também foi uma grande parceira, com a UEMS especificamente nós não temos nenhum convênio, tivemos na época do normal superior. Nós não temos programas com a rede estadual, estamos com convênio com o Estado, com a escola Agrícola e com a Guarani que cedemos o prédio, estão terminando o prédio deles, mas vamos continuar em parceria. (Secretária de Educação de Amambai, gestão 2000-2003 e 2008-2011 - grifo nosso).

Em Naviraí também é apontada a parceria com a UEMS na formação de professores, conforme explicita a transcrição a seguir: ${ }^{6}$

Até 2000, nós tínhamos um número ainda de professores com apenas o magistério e hoje nós não temos nenhum. Foi uma parceria com a UEMS. Foram 6 anos formando professores com políticas para a formação e pós-graduação também, e quem faz nas particulares recebe bolsas que o município proporciona. (Coordenadora pedagógica das séries iniciais da Gerência de Educação de Naviraí, gestão 2008-2011 - grifo nosso).

A gerente de educação de Naviraí (gestão de 2000 a 2004) destacou, também, que o curso normal superior da UEMS contribuiu para a formação de quadros técnicos para atuar junto ao órgão gestor municipal, como foi o caso da professora que ocupa o cargo de coordenadora pedagógica das séries iniciais na Gerência de Educação, setor responsável também pela avaliação do ensino fundamental no município.

Assim como foi enfatizado pelos gestores municipais, os gestores universitários também ressaltaram a contribuição do curso normal superior nos bons resultados do Ideb, conforme expõe o trecho da entrevista com a pró-reitora de Ensino a seguir transcrita: ${ }^{7}$

O curso normal superior [...] que só terminou agora em 2010, esse curso nasceu exatamente para atender os professores da educação básica do Estado do Mato Grosso do Sul, todos aqueles que estavam em sala de aula; com o passar do tempo, atendemos aqueles que não eram efetivos, atendemos os professores que estavam nas creches, então a preocupação era sempre estar atendendo à educação básica, porque essa é, e sempre foi, a missão da UEMS. [...]. Nosso intuito era atender toda a rede municipal e estadual. Fizemos convênios com quase todos os municípios, [...]. Abrimos curso de pedagogia em outros locais, como Paranaíba, outras licenciaturas como história e geografia foram abertas na minha gestão também em Glória de Dourados, em Amambai e sempre a prioridade em cursos de licenciatura [...] estávamos abertos às redes municipais e à estadual para estar atendendo esse tipo de solicitação [...]. (Pró-reitora de Ensino, gestão 2001-2005).

O depoimento da pró-reitora de Ensino da UEMS, na gestão 2001-2005, explicita as iniciativas institucionais voltadas para a formação inicial de professores para a educação básica, especialmente efetivada por meio da ampliação de vagas e cursos destinados à licenciatura. A pró-reitora, em seu depoimento, traduz a política institucional da UEMS e as estratégias para essa efetivação, desencadeada por meio da expansão de cursos regulares voltados para a formação de professores e também por meio da oferta de 
cursos específicos de formação em serviço, como foi o caso do curso normal superior, que teve duração de dez anos.

Especificamente, a ação da universidade, envolvendo as redes estadual e municipais de educação básica no desenvolvimento da formação inicial dos professores, promove impactos no contexto estadual na medida em que viabiliza a formação de 1.438 professores em exercício, distribuídos em diversos municípios do interior do Estado, inclusive naqueles onde não há a presença de cursos de educação superior, privados ou públicos.

De 2000 a 2010, a UEMS ofertou a formação inicial em serviço, por meio do curso normal superior. A primeira oferta da UEMS se deu antes mesmo de iniciativas da União voltadas para essa finalidade.

Entre as medidas federais adotadas, destaca-se a Política Nacional de Formação dos Profissionais do Magistério da Educação Básica, formalizada por meio do Decreto $n^{\circ}$ 6.755, de 29 de janeiro de 2009. Esse decreto, entre outros fatores, visa qualificar docentes em exercício, articulando instituições de educação superior com as redes de educação básica, municipal e estadual, considerando a criação de fóruns estaduais permanentes de apoio à formação docente (Brasil. Decreto..., 2009). Foi com base nessa política que o MEC implantou o sistema eletrônico conhecido como "Plataforma Freire", voltado para a operacionalização da formação em nível de graduação de professores, especialmente em municípios interioranos, por meio de parceria entre universidades, sistemas municipais e estaduais. ${ }^{8}$

Pode-se observar, considerando os depoimentos coletados, que a presença da universidade nas regiões interioranas permite a construção de redes de interação com base no contato direto com as demandas locais, oriundas das instituições de educação básica, o que viabiliza a adoção de medidas e ações específicas e conjuntas na solução dos problemas que se apresentam nesses contextos.

O depoimento ${ }^{9}$ do pró-reitor de Ensino da UEMS (gestão 2005 a 2007) explicita um dos mecanismos institucionais adotados para a integração com o sistema de educação estadual:

[...] apresentar um relatório do vestibular, [...] que acaba sendo um dos meios de avaliação da educação básica, que são os alunos vindos de todos esses níveis de escolaridade e percebemos deficiências desses alunos, passamos a apresentar os relatórios para a secretaria de educação do Estado. Com os resultados do nosso vestibular para que eles pudessem avaliar, considerando que $80 \%$ dos nossos alunos que ingressam na universidade vêm de escolas públicas e desses $80 \%$, mais de $90 \%$ são alunos do Estado do Mato Grosso do Sul. [...] nossos professores, seja de Pedagogia, de Letras, Biologia, começaram a participar dessas reuniões de discussões políticas para a melhoria da educação básica no nosso Estado; são mecanismos criados pela universidade como forma de auxiliar a secretaria de Estado da educação na melhoria da educação básica. (Próreitor de Ensino da UEMS, gestão 2005-2007).

Nesse mesmo sentido, o depoimento da pró-reitora de Extensão, Cultura e Assuntos Comunitários da UEMS $^{10}$ explicita o envolvimento da universidade com as redes municipais de ensino na formação inicial e continuada de professores:
${ }^{8}$ Para mais informações sobre a Plataforma Freire, acessar: < http://freire.mec.gov.br/index/ principal/ >. Acesso em: 10 dez. 2013.

9 Entrevista realizada em 2 de junho de 2010, quando se autorizou o uso das informações.

${ }^{10}$ Entrevista realizada em 28 de maio de 2010, quando se autorizou o uso das informações. 
[...] Entre as diferentes ações da política estabelecida, consideramos que a capacitação de professores e demais profissionais da educação destinada à formação inicial e continuada, constitui-se em um dos fatores principais para o sucesso da educação. Nos municípios de Amambai e Paranaíba, os governos municipais do período em foco estabeleceram a capacitação desses profissionais como prioridade. Para a implementação da mesma, a UEMS foi solicitada e teve participação efetiva tanto na oferta de cursos de formação inicial, Pedagogia em Paranaíba e História em Amambai. (Pró-reitora de Extensão, Cultura e Assuntos Comunitários da UEMS no período de 2003 a 2007).

De forma geral, pode-se inferir que a formação inicial de professores desenvolvida pela universidade potencializa a ação institucional, induzindo o envolvimento na formação continuada de professores, conforme explicitam os depoimentos dos gestores da UEMS e das redes de educação básica, como a secretária municipal de Educação de Paranaíba: ${ }^{11}$

Nós tivemos sim. Nós tivemos uma boa relação, acho que a UEMS tem contribuído muito com a educação do município. Toda vez que procuramos, é que precisamos de alguma coisa, a UEMS sempre teve (sic) pronta e sempre nos atendeu em tudo aquilo que a gente tem pedido. (Secretária de Educação no período de 1997 a 2004).

Pode-se observar que a política de integração da universidade com as redes de educação básica parte essencialmente da criação dos cursos de graduação, conforme traduzem os dados apresentados sobre formação dos professores e os relatos dos gestores educacionais.

Esse dado é interessante quando se observa que no período de análise da atuação da instituição, o qual abarca os anos de 2000 a 2007, deflagra-se no cenário nacional um amplo processo de expansão da educação superior, caracterizado pela privatização do setor e pela diversificação institucional, vindo a propiciar a presença de faculdades, que promovem o ensino superior desvinculado de pesquisa e de extensão, particularmente como único acesso à educação superior em municípios interioranos. Esse movimento é considerado massificação da educação superior, atingindo principalmente a formação de professores, carreira considerada menos atrativa (Freitas, 2007; Cunha, 2004; Catani; Oliveira, 2002; Alves; Pinto, 2011).

A política institucional da UEMS, nesse contexto, constitui-se em um movimento contrário ao processo de expansão das faculdades privadas no estado, que se traduziu na maioria das matrículas da educação superior a partir de 1995 (Real, 2008; Gomes; Moraes, 2009).

A crítica que se pode fazer à política institucional voltada para a integração com a educação básica está na ação focalizada das medidas no ensino de graduação, formuladas e avaliadas empiricamente. Segundo a pró-reitora de Ensino da gestão 2001-2005, o curso normal superior é implantado de acordo com a demanda das redes municipais e estaduais. Para o pró-reitor de Ensino da gestão 2005-2007, a observação e a discussão sobre a qualidade da educação básica são desenvolvidas pelos relatórios dos resultados do vestibular de ingresso à universidade e por reuniões com as redes. Nesse sentido, pode-se inferir que as ações não são respaldadas por resultados de pesquisa nem mesmo por processo de avaliação sistemático,
${ }^{11}$ A entrevista foi realizada em 05 de agosto de 2009, quando se autorizou o uso das informações. 
o que fragiliza as tomadas de decisões de forma racionalizada e permite influências dos interesses e das políticas locais. Conforme alerta Palumbo (1989, p. 59):

O processo de elaboração de políticas em si é incremental por natureza, não racional, altamente político, frequentemente desunido e desconectado. Isso significa que a maioria das decisões referentes às políticas são feitas através de pequenos incrementos, ao invés de saltos, e a reflexão nem sempre precede uma ação; comumente, um indivíduo ou uma agência governamental age primeiro e depois analisa o que foi feito. Geralmente, um governo seleciona uma alternativa que "satisfaça" ao invés de maximizar a realização das metas das políticas. [...]. A satisfação inclui mais do que as metas das políticas; ela considera o apoio político, forças organizacionais e proteção das bases, entre outras coisas. Técnicas para análises de políticas, por outro lado, são baseadas na noção de que, uma vez que a melhor alternativa para o alcance das metas seja identificada, uma organização fará o possível para implementá-la.

Assim, se, por um lado, a presença da universidade nos municípios do interior potencializa a integração com os sistemas de educação básica, propiciando o atendimento às suas demandas, por outro, há a necessidade de se criarem processos avaliativos sistematizados para a política desenvolvida que incluam técnicas de análises e de avaliação de políticas públicas, as quais, embora recentes, são divulgadas no Brasil (ver: Ball; Mainardes, 2011; Figueiredo; Figueiredo, 1986; Palumbo, 1989).

\section{A formação continuada, as ações de extensão e pesquisa}

Em relação à formação continuada, desenvolvida sob a forma de projetos de extensão, não foi possível precisar seus efeitos diretos nos bons resultados do Ideb com base nos dados coletados que consideraram a periodicidade das ações, a quantidade de projetos e de atividades e o número de professores da educação básica envolvidos ao longo do período analisado. No entanto, pode-se inferir que, de forma indireta, promovem processos de integração entre universidade e instituições de educação básica, conforme aponta o depoimento da pró-reitora de Extensão, Cultura e Assuntos Comunitários:

É importante frisar que as ações de formação continuada não se limitaram a um pequeno espaço de tempo e sim elas consistiram em ações contínuas e abrangentes a um grupo expressivo de profissionais e, ainda, por tratar-se de programas, constituem-se em várias ações integradas e complementares, envolvendo os próprios alunos da educação básica, como é o caso de aulas de reforço e projetos culturais, entre outras ações. No município de Naviraí, a interferência da UEMS na capacitação de professores foi mais efetiva na área de Química, oferecendo também projetos aos alunos da educação básica de grande relevância. (Pró-reitora de Extensão, Cultura e Assuntos Comunitários da UEMS no período de 2003 a 2007).

Os projetos de extensão desenvolvidos no período constam na Tabela

2, a seguir: 
Tabela 2 - Projetos de Extensão das Unidades Universitárias da UEMS Localizadas,nos Municípios de Amambai, Naviraí e Paranaíba, na Area de Educação - 2001 a $2007^{(1)}$

\begin{tabular}{l|c|c|c|}
$\begin{array}{c}\text { Unidades } \\
\text { universitárias }\end{array}$ & $\begin{array}{c}\text { Número de } \\
\text { projetos }\end{array}$ & $\begin{array}{c}\text { Público indireto } \\
\text { envolvido }\end{array}$ & $\begin{array}{c}\text { Professores da educação } \\
\text { básica envolvidos }\end{array}$ \\
\hline Amambai & 10 & 1.060 & 473 \\
\hline Naviraí & 7 & 559 & 510 \\
\hline Paranaíba & 23 & 2.407 & 550 \\
\hline
\end{tabular}

Fonte: elaboração própria com base em Mello (2010).

Nota (1): a UEMS não tem dados catalogados dos projetos realizados no período anterior a 2001

Essas ações de formação continuada possibilitam fortalecer as bases de interação. A coordenadora de ensino fundamental da gerência de educação de Naviraí explicita que a parceria com a UEMS possibilitou o uso do laboratório de ciências da universidade para aulas experimentais junto aos alunos das classes de aceleração:

[...] Laboratórios de ciências não temos. Em parceria com a UEMS, em especial, os alunos de aceleração usam esse laboratório, mas não é o ideal. [...] Temos muitos equipamentos, mas o espaço físico não temos. Para não termos salas super lotadas nós acabamos usando esse espaço para as salas. (Coordenadora pedagógica das séries iniciais da Gerência de Educação de Naviraí, gestão 2008-2011 - grifo nosso).

Constata-se, pelos dados apresentados na Tabela 2, que o município em que há a maior concentração de projetos de extensão, Paranaíba, é onde a universidade implantou o curso de mestrado em educação, autorizado pela Coordenação de Aperfeiçoamento de Pessoal de Nível Superior (Capes), ${ }^{12}$ em 2012. Segundo consta na página da UEMS na internet, o mestrado tem "interesse voltado para a produção e socialização de conhecimentos no campo educacional referenciados na crítica aos processos de exclusão social, com atenção ao trabalho com a linguagem, a diversidade e a formação docente" (UEMS, 2012b, grifo nosso). Nesse sentido, pode-se observar o direcionamento desse curso para a formação docente, também visualizada nas duas linhas de pesquisa desenvolvidas: Linguagem, Literatura, Educação; e Sociedade e Teorias e Práticas Educacionais.

Pode-se inferir que, mais do que a pesquisa, a extensão viabiliza as condições de interação entre educação básica e universidade, especialmente considerando que é por meio da quantidade de projetos de extensão voltados para a formação continuada de professores que se efetiva a relação entre professores da educação básica e professores universitários, o que, por sua vez, influencia a construção do curso de pós-graduação stricto sensu em Paranaíba.

Os projetos de pesquisa desenvolvidos no período de 2000 a 2007 estão condensados no Quadro 1.
${ }^{12}$ Homologado pelo CNE por meio da Portaria MEC no 978, de 26 de julho de 2012. 


\section{Quadro 1 - Projetos de Pesquisa das Unidades Universitárias da UEMS Localizadas nos Municípios de Amambai, Naviraí e Paranaíba, na Area de Educação - 2000 a 2007}

\begin{tabular}{|c|c|}
\hline $\begin{array}{c}\text { Unidades } \\
\text { universitárias }\end{array}$ & Títulos dos projetos \\
\hline Amambai & $\begin{array}{l}\text { 1. O aspecto formativo no uso do recurso audiovisual } \\
\text { aplicado ao ensino e o papel desempenhado pelo professor } \\
\text { no processo de formação de conhecimento. } \\
\text { 2. A posse da terra e a fixação do homem no campo e sua } \\
\text { relação com as origens dos assentados. } \\
\text { 3. Plano regional de desenvolvimento sustentável da região } \\
\text { central/Campo Grande: aplicação da técnica Delfos. } \\
\text { 4. A gênese do assentado e sua relação como desenvolvimento } \\
\text { dos assentamentos da reforma agrária. } \\
\text { 5. História Medieval - uma proposta de análise pelo viés } \\
\text { literário. } \\
\text { 6. Uma análise da morte através do romance cavalaria: arts } \\
\text { muriendi na literatura medieval. }\end{array}$ \\
\hline Naviraí & $\begin{array}{l}\text { 1. Valorização do serviço de coleta de lixo: o caso de Naviraí } \\
\text { (MS). } \\
\text { 2. Tecnologias computacionais: o uso de informática na } \\
\text { escola pública e a qualidade do ensino-aprendizagem. } \\
\text { 3. Análise socioambiental em área urbana: o caso da } \\
\text { ocupação das margens do Córrego do Touro em Naviraí } \\
\text { (MS). } \\
\text { 4. Análise de softwares educacionais. } \\
\text { 5. Estudo químico da folha e da casca do caule de guarea } \\
\text { kunthiana a. juss. } \\
\text { 6. As comunidades de peixes e a qualidade da água em } \\
\text { trechos do rio Corumbataí (SP). } \\
\text { 7. Estudo fitoquímico de plantas medicinais e aromáticas do } \\
\text { cerrado e pantanal de Mato Grosso do Sul. } \\
\text { 8. Matemática e biologia: um relacionamento científico } \\
\text { que pode contribuir para eficiência no processo ensino- } \\
\text { aprendizagem. }\end{array}$ \\
\hline Paranaíba & $\begin{array}{l}\text { 1. TV Escola - uma estratégia para a melhoria da qualidade } \\
\text { na educação. } \\
\text { 2. Educação do campo: uma análise da prática avaliativa } \\
\text { docente no projeto "porteiras do saber". } \\
\text { 3. Educação para o campo: uma investigação na rede pública } \\
\text { de Mato Grosso do Sul. } \\
\text { 4. A representatividade dos gêneros textuais nas práticas } \\
\text { comunicativas. } \\
\text { 5. Histórias de vidas: construção da identidade dos } \\
\text { parceleiros do assentamento Serra. }\end{array}$ \\
\hline
\end{tabular}

Fonte: Elaboração própria com base em Mello (2010).

O número de projetos de pesquisa pode ser considerado limitado, em termos quantitativos, e evidenciado, ainda, na assimetria das temáticas. A maioria dos projetos não focaliza a formação docente ou nem mesmo adota a escola como campo empírico dos estudos, como é o caso da pesquisa "As comunidades de peixes e a qualidade da água em trechos do 
rio Corumbataí-SP". Se considerarmos os temas dos projetos de pesquisa com foco na área educacional, a unidade de Paranaíba teria o maior número de projetos voltados para essa temática, embora quantitativamente apresente número menor. Essa evidência consolida as condições favoráveis engendradas pelos projetos de extensão desenvolvidos na unidade para a criação do mestrado em educação.

O mestrado em educação, por sua vez, deve consolidar as ações institucionais na formação de professores, especialmente como formação continuada, uma vez que explicita esse interesse no processo de sua criação e na definição das linhas de pesquisa a serem desenvolvidas.

A UEMS não estabelece política diretiva para o desenvolvimento da pesquisa na área educacional, conforme se pode extrair da Resolução Cepe/ UEMS n ${ }^{\circ} 553$, de 22 de setembro de 2005, que regulamenta o programa de pesquisa da UEMS. No entanto, a partir da implantação da pós-graduação stricto sensu, esse direcionamento pode vir a ocorrer de forma indireta, na unidade universitária em que está implantado.

De forma geral, a definição dos temas de pesquisa é decisão do corpo docente, o que justifica a concentração dos temas de pesquisa nas áreas científicas e em seus campos disciplinares que fazem interface com as licenciaturas, particularmente aquelas que são ofertadas nessas unidades, como Biologia, Química e Letras.

Essa característica presente na opção dos professores para o desenvolvimento de projetos de pesquisa é constatado por Gatti (2010) em pesquisa que aponta que o foco nas áreas específicas do conhecimento pelos docentes da educação superior materializa-se nos currículos dos cursos de licenciatura, o que se constitui como um dos desafios a serem enfrentados pelas políticas educacionais na formação de professores.

Portanto, se a universidade pretende efetivar sua missão voltada para a melhoria da qualidade da educação básica, há a necessidade de estabelecer políticas indutoras para a pesquisa e a extensão focalizando a formação de professores, de forma a potencializar as condições de sua interferência no desenvolvimento educacional para além dos bons resultados obtidos em Paranaíba, Naviraí e Amambai para o total de suas 15 unidades universitárias.

\section{Considerações finais}

Foi possível observar que a universidade interiorizada, particularmente a UEMS, foco deste trabalho, condensa em si condições para interagir de forma mais efetiva com as instituições e redes de educação básica, pois o desenvolvimento de projetos de pesquisa e de extensão, para além da formação inicial de professores, explicita potencial de articulação entre educação superior e educação básica.

Nesse sentido, constatou-se que a realização de programas de formação inicial em serviço, sob a forma de convênios entre as redes municipais e a universidade, além de produzir efeitos na titulação dos professores das 
redes e na formação de seus gestores, trouxe repercussões indiretas, possibilitando maior articulação interinstitucional, que contribuiu na participação em atividades de formação continuada, inclusive viabilizando as bases para a criação de curso de pós-graduação stricto sensu com foco na formação de professores, implantado no interior do Estado.

As ações desenvolvidas por meio de projetos de extensão e de pesquisa demonstraram contribuir para a construção de um lócus de articulação e de diálogo entre a universidade, os órgãos de administração e as instituições de educação básica, estabelecendo condições para o desenvolvimento de relações efetivas e longitudinais.

No entanto, constatou-se a ausência de políticas institucionais específicas nessa direção, em que as ações desenvolvidas estão sob a responsabilidade e o arbítrio direto e exclusivo dos professores universitários, que desenvolvem projetos de pesquisa e de extensão de forma a reproduzir o foco nas áreas específicas do conhecimento em detrimento das áreas pedagógicas propriamente ditas. Apontou-se, também, a necessidade de se estabelecerem técnicas de análises e de avaliação das políticas institucionais, para que sejam fortalecidas as bases racionais para as tomadas de decisões, especialmente considerando a interface política presente na interação junto aos sistemas educacionais municipais.

Observou-se que a UEMS não promove políticas institucionais indutoras de ações docentes com esse fim, embora conste nas normas institucionais que sua missão incide em melhoria da qualidade da educação básica no Estado de Mato Grosso do Sul.

Ainda considerando o caráter exploratório do presente estudo, pode-se inferir que a contribuição direta da UEMS está na formação inicial de professores e de gestores para a educação básica, uma vez que a política institucional parece estar direcionada para esse fim, embora haja potencial de intensificação das ações de pesquisa, extensão e de pós-graduação stricto sensu.

Esses dados, embora tenham como referência lócus empírico particular, trazem elementos que problematizam análises presentes na literatura da área educacional que explicam o movimento de expansão da educação superior para o interior do País, após o governo militar, caracterizado como "paroquialização" (Oliven, 1990; Cunha, 2004) - o que, a priori, inviabilizaria o uso dessa expressão para o atual contexto.

Em síntese, o presente estudo exploratório explicita a necessidade de realização de novos estudos longitudinais de monitoramento da relação entre universidade e sistemas de educação básica localizados em municípios interioranos, não só no Estado de Mato Grosso do Sul, mas também em todo o contexto brasileiro. Esses estudos se fazem necessários, especialmente no tempo presente, quando novas políticas educacionais voltadas para a expansão da educação superior pública são formuladas, inclusive com foco na sua interiorização. 


\section{Referências bibliográficas}

ALVES, F. Políticas educacionais e desempenho escolar nas capitais brasileiras. Cadernos de Pesquisa, São Paulo, v. 38, n. 134, p. 413-440, 2008.

ALVES, F. Qualidade na educação fundamental pública nas capitais brasileiras: tendências, contextos e desafios. Belo Horizonte:

Argvmentvm, 2009.

ALVES, T.; PINTO, J. M. de R. Análise das características do trabalho e da remuneração docente no Brasil a partir das bases de dados demográficas e educacionais. In: REUNIÃO ANUAL DA ANPED, 34., 2011, Rio de Janeiro. Anais eletrônicos... Rio de Janeiro: ANPED, 2011. Disponível em: <http://34reuniao.anped.org.br/images/trabalhos/GT05/ GT05-735\%20int.pdf>. Acesso em: 13 dez. 2013.

BALL, S. J.; MAINARDES, J. (Org.). Políticas educacionais: questões e dilemas. São Paulo: Cortez, 2011.

BRASIL. Conselho Nacional de Educação. Parecer CNE/CES no 244. Assunto: Reconhecimento dos programas de pós-graduação stricto sensu (Mestrado e Doutorado), recomendados pelo Conselho Técnico e Científico - CTC da CAPES, na reunião realizada em 28 de fevereiro e $1^{\circ}$ de março de 2011 (124ª Reunião). Parecer aprovado em 5 mar. 2011.

BRASIL. Coordenação de Aperfeiçoamento de Pessoal de Nível Superior (Capes). Mestrados/doutorados reconhecidos. Brasília, DF: CAPES, 2012. Disponível em: <http://conteudoweb.capes.gov.br/conteudoweb/Projeto RelacaoCursosServlet?acao $=$ detalhamentoIes\&codigo Programa $=510040$ 11004P9>. Acesso em: 13 out. 2012.

BRASIL. Decreto no 6.755, de 29 de janeiro 2009. Institui a Política Nacional de Formação de Profissionais do Magistério da Educação Básica, disciplina a atuação da Coordenação de Aperfeiçoamento de Pessoal de Nível Superior - Capes no fomento a programas de formação inicial e continuada, e dá outras providências. Diário Oficial da União, Brasília, DF, 30 jan. 2009. Disponível em: <http://www.planalto.gov.br/ ccivil_03/_ato2007-2010/2009/Decreto/D6755.htm>. Acesso em: 13 set. 2012.

BRASIL. Instituto Nacional de Estudos e Pesquisas Educacionais Anísio Teixeira (Inep). Censo da educação superior: 2007. Brasília, DF: Inep, 2008. Disponível em: <http://www.inep.gov.br/superior/censosuperior/ sinopse/defaut.asp>. Acesso em: 04 maio 2008. 
BRASIL. Instituto Nacional de Estudos e Pesquisas Educacionais Anísio Teixeira (Inep). Censo do professor 1997: perfil dos docentes de educação básica. Brasília, DF: Inep, 1999. Disponível em: <http://portal. inep.gov.br/profissionais-do-magisterio >. Acesso em: 4 maio 2008.

BRASIL. Ministério da Educação (MEC). Portaria nº 978, de 26 de julho de 2012. Diário Oficial da União, Brasília, DF, 27 jul. 2012. Seção 1, p. 9.

BROOKE, N.; SOARES, J. F. (Org.). Pesquisa em eficácia escolar: origem e trajetórias. Belo Horizonte: Ed. UFMG, 2008.

CATANI, A. M.; OLIVEIRA, J. F. de. Educação superior no Brasil: reestruturação e metamorfose das universidades públicas. Petrópolis: Vozes, 2002.

CUNHA, L. A. Desenvolvimento desigual e combinado no ensino superior: Estado e mercado. Educação \& Sociedade, Campinas, v. 25, n. 88, p. 795-817, 2004.

FIGUEIREDO, M. F.; FIGUEIREDO, A. M. C. Avaliação política e avaliação de políticas: um quadro de referência teórica. Análise \& Conjuntura, Belo Horizonte, v. 1, n. 3. set./dez. 1986.

FREITAS, H. C. L. de. A (nova) política de formação de professores: a prioridade postergada. Educação \& Sociedade, Campinas, v. 28, n. 100, p. 1203-1230, 2007.

GATTI, B. A. Formação de professores no Brasil: características e problemas. Educação \& Sociedade, Campinas, v. 31, n. 113, p. 1355-1379, 2010.

GOMES, A. M.; MORAES, K. M. A expansão da educação superior no Brasil contemporâneo: questões para o debate. In: REUNIÃO ANUAL DA ANPED, 32., 2009, Caxambu. Anais... Rio de Janeiro: Anped, 2009. Disponível em: <http://www.anped11.uerj.br/32/gt11-5848--int.pdf >.

MELlO, V. A. de. A expansão da educação superior pela estratégia da interiorização: nexos com os bons resultados do Ideb em Mato Grosso do Sul. 2010. 174 f. Dissertação (Mestrado em Educação) - Universidade Federal da Grande Dourados, Dourados, 2010.

OLIVEN, A. C. A paroquialização do ensino superior: classe média e sistema educacional no Brasil. Petrópolis: Vozes, 1990.

PALUMBO, D. J. A abordagem de política pública para o desenvolvimento político na América. In: POLÍTICA de capacitação dos profissionais da educação. Belo Horizonte: FAE/ITHJP, 1989. p. 35-61. 
PARANDEKAR, S. D; OLIVEIRA, I. de A. R. de; AMORIM, E. P. (Org.). Desempenho dos alunos na Prova Brasil: diversos caminhos para o sucesso educacional nas redes municipais de ensino. Brasília, DF: Inep, 2008.

REAL, Giselle Cristina Martins. Impactos da avaliação na educação superior. Dourados, MS: Ed. UFGD, 2008.

SEVERINO, A. J. Expansão do ensino superior: contextos, desafios, possibilidades. Avaliação, Campinas, v. 14, n. 2, p. 253-266, 2009.

SOUSA, S. Z.; OLIVEIRA, R. P. de; ALAVARSE, O. M. Políticas educacionais municipais e qualidade do ensino: o Ideb como mecanismo de monitoramento da educação fundamental. In: FREITAS, D. N. T. de; REAL, G. C. M. (Org.). Políticas e monitoramento da qualidade do ensino fundamental: cenários municipais. Dourados: Ed. UFGD, 2011. p. 13-23.

UNIVERSIDADE ESTADUAL DE MATO GROSSO DO SUL (UEMS). Resolução CEPE/UEMS $n^{\circ} 553$, de 22 de setembro de 2005. Homologa a Deliberação $n^{\circ}$ 004, de 8 de setembro de 2005, da Câmara de Pesquisa e Pós-Graduação do Conselho de Ensino, Pesquisa e Extensão, que aprova o Regulamento do Programa de Pesquisa da Universidade Estadual de Mato Grosso do Sul e revoga a Resolução CEPE/UEMS no 363, de 25 de março de 2003, com alterações. Dourados: UEMS, 2005. Disponível em: <http://www.uems.br/propp/conteudopesquisa/normatizacao.htm>. Acesso em: 25 out. 2009.

UNIVERSIDADE ESTADUAL DE MATO GROSSO DO SUL (UEMS). Mestrado em educação. Dourados: UEMS, 2012b. Disponível em: <http://www.uems.br/pgedu/>. Acesso em: 10 out. 2012.

UNIVERSIDADE ESTADUAL DE MATO GROSSO DO SUL (UEMS). Missão. Dourados: UEMS, 2012a. Disponível em: <http://www.uems.br/ portal/missao.php>. Acesso em: 29 set. 2012.

Giselle Cristina Martins Real, doutora em Educação pela Universidade de São Paulo (USP), é professora adjunta da Universidade Federal da Grande Dourados (UFGD), atuando na graduação e na pós-graduação stricto sensu, Dourados, Mato Grosso do Sul, Brasil.

gcreal@terra.com.br

Recebido em 13 de janeiro de 2014.

Aprovado em 30 de julho de 2014. 